\title{
A THERMODYNAMIC APPROACH TO BIOLOGICAL INVASIONS
}

\author{
N. MARCHETTINI ${ }^{1}$, M. MARCHI ${ }^{1}$, I. CORSI $^{2} \&$ E. TIEZZI ${ }^{1, \dagger}$ \\ ${ }^{1}$ Department of Chemistry, University of Siena, Italy \\ ${ }^{2}$ Department of Environmental Sciences "G. Sarfatti”, University of Siena, Italy
}

\begin{abstract}
True acetylcholinesterase (AChE), an important polymorphic enzyme of the nervous system, was studied to determine the inhibition of transmission of nerve impulses in muscles of the red swamp crayfish, Procambarus clarkii, exposed in vitro to organophosphate (OP) insecticides. The species showed moderate sensitivity to OP insecticides, confirming a factor of its invasive capacity in Mediterranean freshwater and brackish environments. The half maximal inhibition concentration $\left(\mathrm{IC}_{50}, \mathrm{M}\right)$ for $\mathrm{AChE}$ vs. acetylthiocholine activity (ASCh, 1 $\mathrm{mM}$ ) in P. clarkii was compared with that of different tissues of various aquatic invertebrates recently described as invasive and with other non-invasive species. The results suggest that non-invasive species have a lower capacity than invaders to regulate transfer of nerve impulses across synapses, favoring an overall increase in their internal entropy. On the other hand, invasive species seem to have a high capacity to self-organize and produce negentropic internal processes, even though in many cases their strong adaptive capacity can be deleterious for the complexity and equilibrium of the community into which they are introduced, favoring an overall increase in entropy of the ecosystem. The internal complexity of the invasive species considered in this study is discussed in terms of evolutionary thermodynamics with particular emphasis on entropy production and related information.

Keywords: acetylcholinesterase activity, OP insecticides, entropy, complexity, biotic invasions, evolutionary thermodynamics
\end{abstract}

\section{INTRODUCTION}

The adaptive success of many alien species depends on their strong competition for resources and high reproductive capacity. For example, they are capable to withstand environmental stresses such as high temperatures, pollution, changes in water quality, salinity and oxygen concentrations. Native species may be more sensitive to environmental stressors and therefore less able to cope with chemical and thermal pollutions or competition for food. Their exotic rivals may be more aggressive and flexible [1].

Investigators have tried to characterize morphological, physiological and biological properties that could serve as reliable indicators for an animal or plant species to behave as an invader [2]. For example, the resistance of certain species to in vitro exposure of organophosphate (OP) insecticides, even at high concentrations, favors hydrolysis of the neurotransmitter acetylcholine (ACh) due to modified forms of acetylcholinesterases (AChEs), polymorphic enzymes involved in transmission of nerve impulses at synapses. This behavior can be interpreted as a molecular property of organisms with evolutionary characteristics typical of potentially invasive species. In fact, OP insecticides are anti-AChE compounds that can occupy the active site of AChE or an adjacent domain, preventing access to the natural substrate (ACh) and its further catalysis. OP insecticides are highly toxic. They prevent muscle relaxation [3], cause tremor, convulsions and death by asphyxia due to paralysis of respiratory muscles [4]. Nevertheless, preliminary investigations seem to suggest that invasive species may have a better capability to cope with OP insecticides exposure than indigenous species and thus

\footnotetext{
`This article is co-authored by Professor Enzo Tiezzi who died soon after the paper was submitted for publication. The Editors would like to dedicate this publication to the memory of Enzo, whose obituary appears in Vol. 5, No. 2, 2010.
} 
a greater ability to survive [5]. This is why resistance to exposure to OP insecticides may be considered as a physiological indicator of the health status of an organism: in the case of resistance, OPs are unable to bind to AChE, favoring a decrease in entropy within the organism. It appears that invasive species are subject to particular evolutionary adaptations that favor their resistance and survival under such harsh environmental conditions as pollution.

The aim of the present study was to investigate and to compare the capacity of invasive species to regulate their internal entropy by using genetic adaptive mechanisms, such as the presence of OP-resistant forms of AChE. We analyzed the AChE response of Procambarus clarkii (Girard 1852), an invasive crustacean in Mediterranean freshwater and brackish environments [6, 7], exposed to OP insecticides in vitro. To reveal differences characterizing the physiological response of invaders with respect to non-invasive species, the results were compared with the data obtained from other aquatic invertebrates, which have been recently recognized as invasive, and from noninvasive species [8-10]. The Wicken equations [11-14] provided insights into the degree of chemical complexity of a thermodynamic system in terms of information. So, we have resorted to these equations in order to distinguish the molecular properties of invaders from those of non-invasive species, using the information theory, which is an integral part of the evolutionary thermodynamics.

Although generalizations are impossible, detailed study of the genetic and the behavioral characteristics of a species, besides those of the habitat into which they are introduced, make it possible to predict invasive capacity. Evolutionary thermodynamics can promote understanding of this complex phenomenon $[15,16]$.

\section{MATERIALS AND METHODS}

\subsection{Sampling and biochemical analysis}

Male and female specimens of $P$. clarkii were caught by net and by hand in Accesa Lake, near Massa Marittima (southern Tuscany, Italy). A total of 14 specimens ( 9 adult males, 5 adult females) of similar sizes (males $6.7-8.7 \mathrm{~cm}$, females $6.8-9.2 \mathrm{~cm}$ ) were analyzed. All females except one contained eggs at the time of capture, and therefore had larger abdomens.

AChE was extracted from muscle in the proportion $0.1 \mathrm{~g} \mathrm{ml}^{-1}$ in ice-cold $20 \mathrm{mM}$ Tris- $\mathrm{HCl}, 5 \mathrm{mM}$ $\mathrm{MgCl}_{2}, 0.1 \mathrm{mg} \mathrm{ml}^{-1}$ bacitracin, $8 \times 10^{-3} \mathrm{TIU} \mathrm{ml}^{-1}$ aprotinin and $1 \%$ Triton X-100 (pH 7.6). Tissue was first cut up finely with scissors, then homogenized in a potter-Elvenjem glass/Teflon homogenizer at $2000 \mathrm{rpm}$ and finally in an Ultraturrax at $8400 \mathrm{rpm}$ for $20 \mathrm{~min}$ at $4^{\circ} \mathrm{C}$. After centrifuging, the pellet containing cell debris was discarded, and the supernatant was immediately analyzed.

Selective inhibitions of AChE were measured on microplates by the method of Ellman et al. [17] for three different $\mathrm{OP}$ insecticides at concentrations in the range $10^{-10}$ to $10^{-3} \mathrm{M}$ : diisopropylfluorophosphate (DFP), dichlorvos and chlorpyriphos. Assays were performed at $30^{\circ} \mathrm{C}$ in $0.1 \mathrm{M} \mathrm{Na}_{2} \mathrm{PO}_{4}$

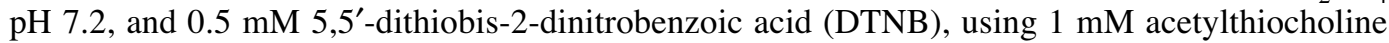
iodide (ASCh). The variation in absorbance at $405 \mathrm{~nm}$ was followed for $5 \mathrm{~min}$ using a Bio-Rad model 550 microplate reader. Enzyme activity was expressed in $\mathrm{nmol} \mathrm{min}^{-1} \mathrm{mg}$ protein ${ }^{-1}$. $\mathrm{IC}_{50}$ (50\% inhibition of hydrolysis of the substrate ACh) was calculated for AChE vs. ASCh activity (1 $\mathrm{mM})$. OP insecticides were incubated with crude homogenates for $15 \mathrm{~min}$ at $30^{\circ} \mathrm{C}$ before substrate kinetic study. Stock solutions of selective inhibitors and insecticides were prepared in methanol. A control vehicle was included for each experimental run and the rate of spontaneous hydrolysis calculated as before. Protein concentrations were measured by the method of Bradford [18] using BSA as standard. 


\subsection{Data for the comparison}

The references we chose for comparison of experimental data of $P$. clarkii with other species regarded studies conducted in the Laboratory of Indicators of Stress of the Ecophysiology and Ecology Applied to Global Changes of the Department of Environmental Sciences "G. Sarfatti", University of Siena, in different research projects over the years [8-10].

Not by chance, we chose data processed in the laboratory in which the studies on P. clarkii were conducted: the methods and equipment were identical in all cases, to minimize errors in the comparison of results.

The data concerned in vitro exposure of OP insecticides on different tissues of various aquatic invertebrates, recognized as invasive and non-invasive: Mytilus galloprovincialis, Sabella spallanzanii, Adamussium colbecki, Pecten jacobaeus, Anodonta sp. and Anodonta woodiana.

The Mediterranean mussel M. galloprovincialis and the Mediterranean fan-worm S. spallanzanii, species alien to the coasts of South Africa and Australia, respectively, showed high resistance of $\mathrm{AChEs}$ to OP insecticides [8] with an $\mathrm{IC}_{50}$ of $10^{-2} \mathrm{M}$ in gills. Their resistance may be an evolutionary adaptation to the pressure of exposure to OP insecticides [19-21].

As concerns the marine bivalves $A$. colbecki, an Antarctic scallop, and the Mediterranean $P$. jacobaeus, both known as non-invasive species, the absence of resistance was indicated by high sensitivity to DFP and azamethiphos (range $10^{-7}$ to $10^{-6} \mathrm{M}$ ) in gills and adductor muscle [10].

In this case, habitat also plays an important role from the ecological point of view: for example, resistance to other OP insecticides, such as fenitrothion and azamethiphos, in gills of the Antarctic scallop [8] may be due to exposure to toxic strains of Antarctic cyanobacteria which produce an anti$\mathrm{AChE}$, anatoxin-a, which has properties similar to an OP insecticide.

Another study compared OP resistance in two freshwater mussels, indigenous Anodonta sp. and the invasive species $A$. woodiana. Although the invasive species was not particularly resistant, it showed greater hydrolytic efficiency and greater AChE content than the indigenous species. A better capacity for enzyme recovery after exposure to OP insecticides and greater resistance to environmental contamination was postulated [9].

\subsection{The components of chemical information}

For the interpretation of the analytical results obtained by the exposure to OP insecticides of $P$. clarkii and the other aquatic invertebrates chosen for the comparison, we used the equations on the information theory proposed by Wicken in the 1970s, with the aim of analyzing the thermodynamic properties that distinguish the invasive species from the non-invasive invertebrates from the theoretical point of view.

The macroscopic thermodynamic information of a system in a given state, for example, the information of the biological organization deriving from specific molecular sequences into an organism $\left(I_{M}\right)$, can be written as follows:

$$
I_{M}=I_{w}+I_{e}
$$

where $I_{w}=-k \ln W_{i}=-S$ is the negentropic component of chemical information and $I_{e}=\left(E_{i}-\bar{A}\right) / T$ is the energy component that is related to entropy output from the system due to energy dissipation. Negentropy is, therefore, expressed by:

$$
I_{w}=I_{t h}+I_{c}
$$


where $I_{t h}$ is thermal information and $I_{c}$ is configurational information. The former refers to the distribution of thermal energy in the given state and the latter to the number of microstates in any possible configuration $[13,14]$.

\section{RESULTS}

Experimental data show that $P$. clarkii is characterized by moderate resistance of AChE activity in muscle exposed to dichlorvos and chlorpyriphos (range $10^{-5}$ to $10^{-3} \mathrm{M}$ ), but high sensitivity to the more toxic DFP (range $10^{-7}$ to $10^{-6} \mathrm{M}$ ). Figure 1 presents inhibition of AChE vs. ASCh activity in muscle of male and female specimens of $P$. clarkii for increasing concentrations of pesticide.

The assay data show a difference of approximately one order of magnitude in sensitivity between male and female specimens:

a. exposure to DFP revealed greater resistance of females $\left(1.96 \times 10^{-6} \mathrm{M}\right)$ than males $\left(1.62 \times 10^{-7} \mathrm{M}\right)$;

b. exposure to dichlorvos did not reveal any major differences between males and females $\left(6.76 \times 10^{-5}\right.$ and $2.53 \times 10^{-5} \mathrm{M}$, respectively);

c. males were more sensitive $\left(2.34 \times 10^{-5} \mathrm{M}\right)$ than females $\left(1.27 \times 10^{-3} \mathrm{M}\right)$ to chlorpyriphos.

Moreover, Table 1 gives the $\mathrm{IC}_{50}(\mathrm{M})$ of AChE vs. $1 \mathrm{mM}$ ASCh activity in crude homogenates of muscle of P. clarkii and those obtained by Corsi et al. [8,9] and Romani et al. [10] in different tissues of various aquatic invertebrates recently described as invasive and non-invasive species.

Comparison of these values shows that, like P. clarkii, the other invasive aquatic invertebrates chosen (M. galloprogincialis, S. spallanzanii and A. woodiana) have specific characteristics that favor the resistance to these agricultural pesticides and present either high values of $\mathrm{IC}_{50}$ or a great hydrolytic efficiency, although differences between tissues, individuals and species.

On the other hand, the non-invasive species (A. colbecki, P. jacobaeus and Anodonta sp.) have $\mathrm{AChE}$ forms that are more sensitive to these contaminants, showing lower $\mathrm{IC}_{50}$ then invasive species. The moderate sensibility of $P$. clarkii to the exposure of OP insecticides confirms its possible invasive capacity in the ecosystems of introduction, a consideration that can also be valid for the other aquatic invertebrates with the same characteristics of resistance to pollution.

\section{DISCUSSION}

Animals surviving challenges communicate with other animals and the environment through collection, elaboration and transmission of information, providing fast coordinated responses. Nerve impulses have to be transmitted quickly if they are important for behavioral adaptation of an animal to its environment [22].

Nervous systems, therefore, evolved to produce fast responses to stimuli, favoring correct metabolic processes that build the complexity of organisms. Increasing complexity and self-organization play a fundamental role in living systems and are related to emergence of novelties and the capacity of systems to self-organize and reduce entropy [23]. This self-organization implies a drastic decrease in entropy because fast correct metabolic processes favor an increase in organism complexity.

Little is known about the genetic origins of resistance at molecular level, though several point mutations in AChE, imparting variable resistance patterns, have been detected in the same catalytic subunit [21]. One of these origins is the intensive use of OP insecticides that has led to the emergence of insect species with an AChE which is less sensitive to OPs, a phenomenon already described in several aquatic invertebrates, as well. This resistance seems related to particular phenotypes bearing substitutions of specific amino acids at the binding site [24]. 

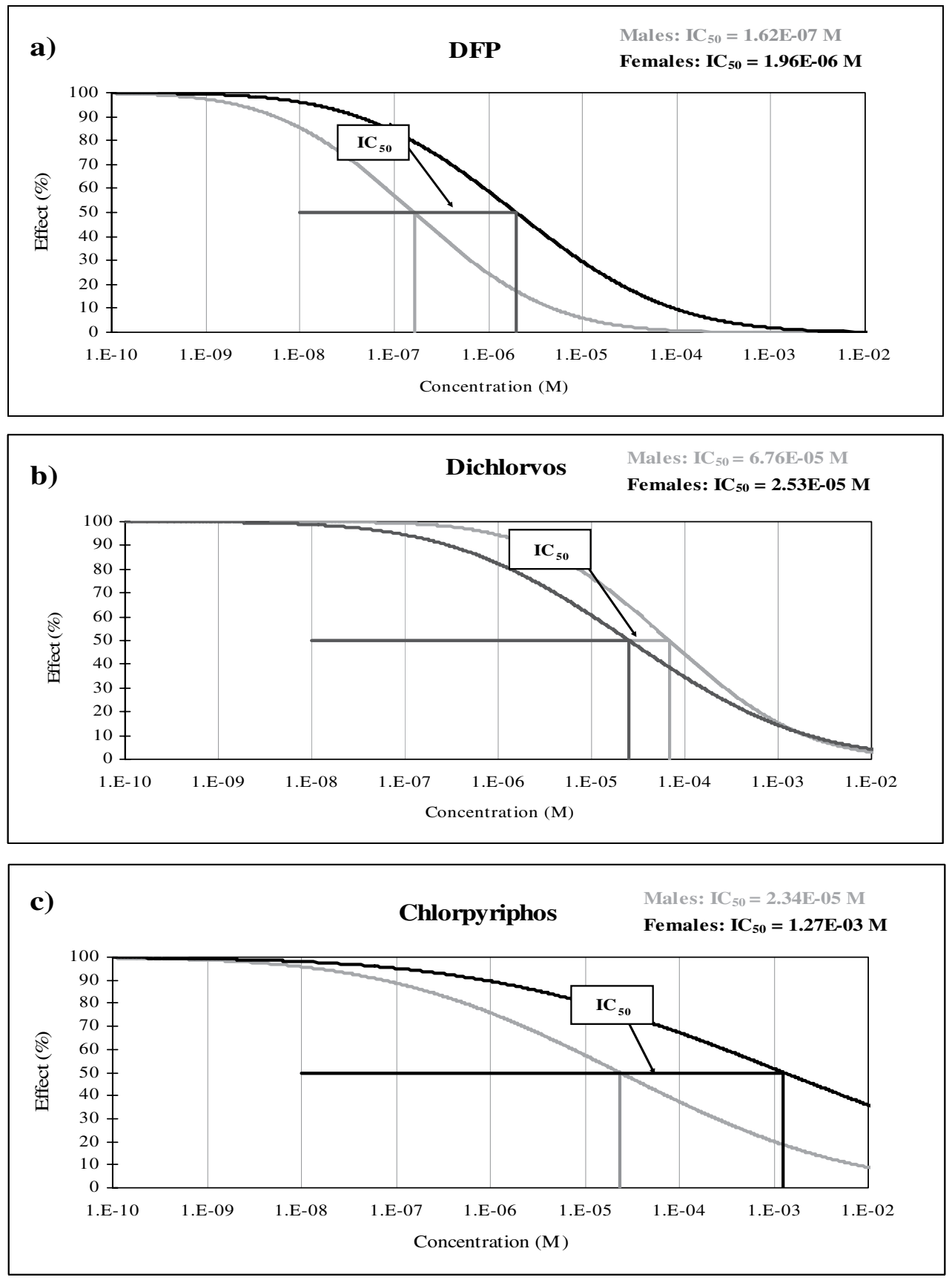

Figure 1: Dose-response curve of AChE vs. ASCh activity $(1 \mathrm{mM})$ to increasing concentrations of organophosphate insecticides in muscle of $P$. clarkii: differences between males and females. 
In the special case of $P$. clarkii, the total moderate sensitivity to OP insecticides suggests that pollution may be a selective factor and that this species has better enzyme recovery than the Mediterranean indigenous species, Austropotamobius pallipes, that has declined sharply in response to pollution, drought, competition from non-native species and diseases [25, 26]. Moreover, the different sensitivity between males and females suggests that females have better defences, presumably due to conservation strategies that make them more resistant to pollution. The fact that most females contained mature eggs when caught confirms good resistance that would protect reproduction. These results suggest that females could be more efficient than males in lowering their internal entropy and increasing their level of complexity; males, in fact, express altered physiological effects sooner because they are unable to regulate their homeostasis so quickly.

Indeed, the inhibition curves (Fig. 1) show that females exposed to DFP and Chlorpyriphos have lower internal entropy production than males in response to increasing concentration of insecticide, whereas males approach thermodynamic equilibrium more rapidly.

The comparison between the values of $\mathrm{IC}_{50}$ of $P$. clarkii and the other invasive and the non-invasive invertebrates presented in Table 1 suggests that the alien species considered in this study have greater resistance to these specific $\mathrm{AChE}$ inhibitors than indigenous species. The invasive species examined seem to suffer only minor physiological effects from exposure to OP insecticides, unlike the other aquatic invertebrates.

In many cases, alien species are characterized by specific evolutionary variations that seem to favor better regulation of internal entropy. Certain physiological properties that cooperate with beneficial behavioral and morphological traits favor a decrease in entropy. Thus, greater resistance increases negentropic trends in the invasive organisms, enhancing their subsistence and working capacities. For example, genetic mutations that lead to synthesis of forms of AChE resistant to OP insecticides help keep organisms in good health.

Organisms that have not developed resistant forms of AChE, through genetic mutations or rapid enzyme recovery, seem to have lower adaptive capacity than their counterparts, which survive even in the presence of contaminants. Exposure to OP insecticides leads to loss of $I_{c}$ (configurational information) of the active site of the enzyme AChE, as eqns (1) and (2) suggest. The covalent bond between the insecticide and the enzyme alters active site structure, causing loss of the information contained in the original microstate, which by no longer interacting correctly with the substrate, leads to an overall increase in the entropy of the organism. With inhibition of the enzyme AChE, less energy is dissipated because the correct physiological mechanisms of nerve impulse transmission between synapses are altered and the biochemical conformation of the active site is lost.

These deductions suggest that the alien species considered in the present study have a greater capacity for exchanging their entropy production with the external environment than more vulnerable non-invasive species. Moreover, the latter have a level of internal information that reduces their capacity to do work, manifesting as slower or completely inhibited metabolic processes. Indeed, in the case of non-invasive aquatic invertebrates, the nerve impulse does not reach effector organs fast enough for correct metabolic functioning, as suggested also by the low values of $\mathrm{IC}_{50}$ shown in Table 1 .

The presence of contaminants inside the organism causes an increase in the interactions possible between molecules, favoring the emergence of new structures, such as the enzyme-insecticide complex. Despite this, the loss of information contained in the active site of AChE alters normal metabolic processes, a phenomenon that may also lead to death of the organism. The increase of the number of microstates (in this case the enzyme-insecticide complexes), that results from an increase in associative reactions or in heterogeneity of molecular species, can trigger incorrect metabolic processes that damage health, unless specific forms of resistance develop, as seen in the invasive aquatic invertebrates of the present study. Indeed, forms of AChE resistant to OP insecticides determine a 


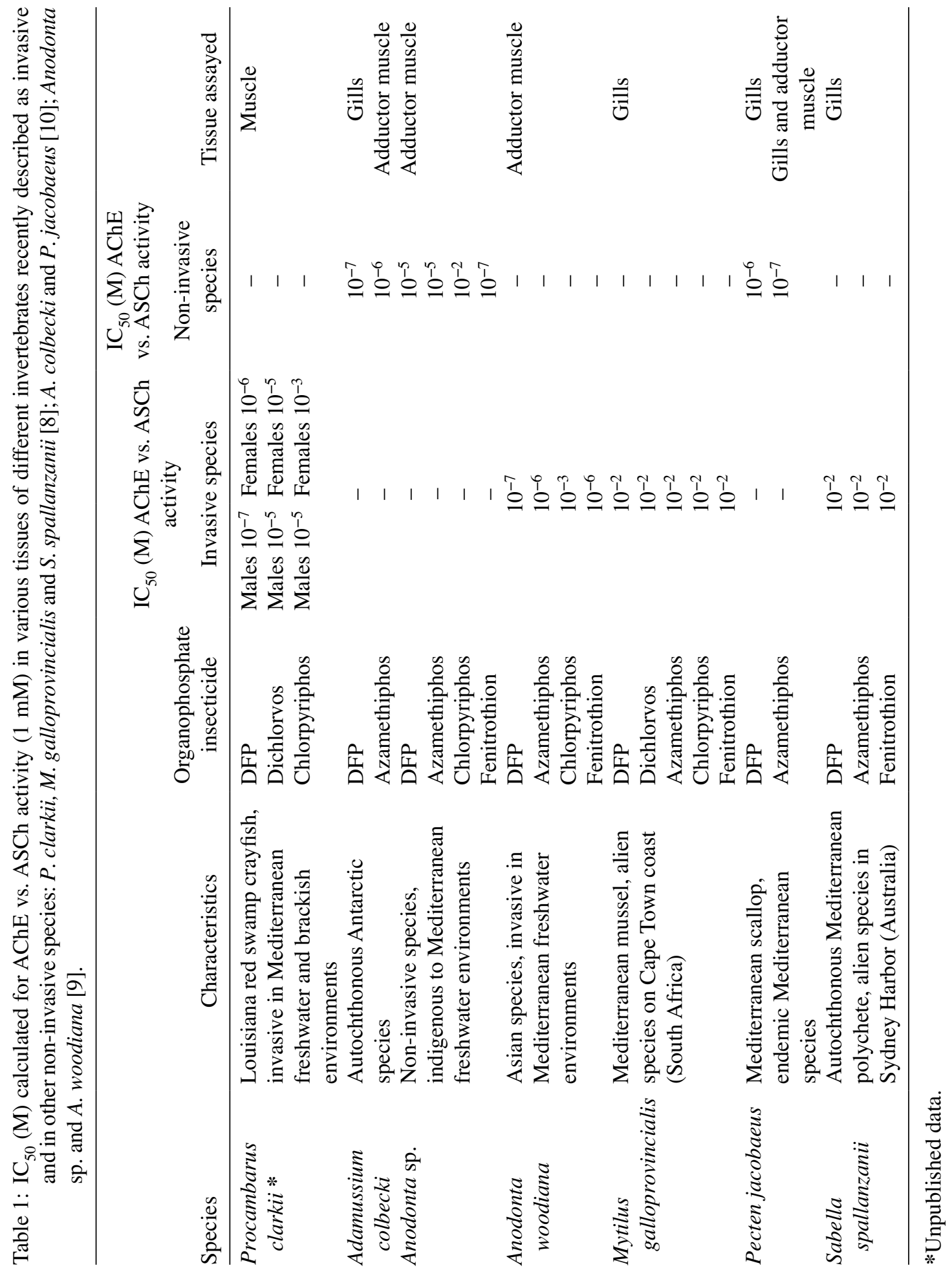


reduction in dangerous physiological effects, and hence an improvement in internal functional properties, a phenomenon that characterizes invasive species.

It, therefore, seems a valid hypothesis that the invasive invertebrates considered in the present study have a higher capacity for $I_{e}$ dissipation than the non-invasive species. It is also important to consider that many of the available routes for this type of dissipation require increase in $I_{t h}$ (thermal information) or structuring, phenomena that favor the development in complexity. In most cases, indeed, invaders show chemicophysical characteristics that reflected genetic mutations or particular phenotypic specializations, manifesting as greater capacity to self-organize than shown by noninvasive species.

The AChE molecule is functional if it promotes a correct physiological process, contributing to health of the organism and favoring its thermodynamic stability, and consequently growth, reproduction and adaptation to its environment. Organisms are thermodynamic systems that maintain their non-equilibrium order by degrading exogenous free energy to entropy, but sensitive non-invasive species seem to have a lower level of internal complexity than invaders, which through better generation of functional organization exploit feedbacks that favor negentropic processes.

Although invasive species have a clear capacity to self-organize, they can be the cause of many changes affecting indigenous communities of ecosystems into which they are introduced. In fact, when invasive species expand their habitat and biomass in an uncontrolled way without competition from their natural predators or other external inputs, the more sensitive native species could suffer and their numbers could decline as a result of increasing vulnerability to environmental change. The entropy of the whole ecosystem could therefore increase, since most ecosystems are subject to strong external pressures [5].

\section{CONCLUSION}

Living systems try to avoid thermodynamic equilibrium, keeping themselves as far as possible from it by self-organizing. This process is powered by flows of matter and energy received from outside and from systems with different temperature and energy conditions. It has been shown that aquatic invaders seem to achieve thermodynamic success due to their capacity to self-organize. The entropy contribution of invasive species is maintained negative (good) through reproduction, metabolic success and an increase in embodied information. A decrease in internal entropy of an organism is a good physiological indicator of its health status and evolutionary complexity. Despite their greater capacity to self-organize than non-invasive species, the aquatic invaders studied here may cause an increase in entropy of the whole ecosystem into which they are introduced (freshwater environments and oceans), damaging indigenous communities. In fact, introduction of alien species can often alter the biogeochemical cycles and equilibria that characterize the ecological webs of the ecosystems of introduction, contributing to a loss of complexity of the system. Moreover, the degree of inhibition of AChE activity after exposure to increasing concentrations of specific inhibitors may be an index for experimental quantification of changes, in part, of the total internal entropy of an organism.

\section{ACKNOWLEDGEMENTS}

Our sincere thanks to Francesco Nardi and Angela Maria Pastore for their help in the laboratory analysis. The authors also thank Simone Bastianoni for the precious comments and discussion.

\section{REFERENCES}

[1] Mack, R.N., Simberloff, D., Lonsdale, W.M., Evans, H., Clout, M. \& Bazzaz, F.A., Biotic invasions: causes, epidemiology, global consequences and control. Ecological Applications, 10(3), pp. 689-710, 2000. doi:10.1890/1051-0761(2000)010[0689:BICEGC]2.0.CO;2 
[2] Williamson, M., Biological Invasions. Chapman \& Hall: London, 1996.

[3] Grue, C.E., Hart, A.D.M. \& Mineau, P., Biological consequences of depressed brain cholinesterase activity in wildlife. Mineau, P., (Ed.) Chemicals in Agriculture. Cholinesterase-inhibiting Insecticides. Elsevier, Amsterdam, pp. 151-209, 1991.

[4] Zinkl, J., Lockhart, W.L., Kenny, S.A. \& Ward, F.J., The effects of cholinesterase inhibiting insecticides on fish. Mineau, P., (Ed.) Chemicals in Agriculture. Cholinesterase-inhibiting Insecticides. Elsevier: Amsterdam, pp. 233-254, 1991.

[5] Marchi, M., Corsi, I. \& Tiezzi, E., Biological invasions and their threat to ecosystems: two ways to thermodynamic euthanasia. Ecological Modelling, 221(5), pp. 882-883, 2010. doi:10.1016/j.ecolmodel.2009.11.020

[6] Gherardi, F. \& Acquistapace, P., Invasive crayfish in Europe: the impact of Procambarus clarkii on the littoral community of a Mediterranean lake. Freshwater Biology, 52, pp. 1249-1259, 2007. doi:10.1111/j.1365-2427.2007.01760.x

[7] Rodríguez, C.F., Bécares, E., Fernández-Aláez, M. \& Fernández-Aláez, C., Loss of diversity and degradation of wetlands as a result of introducing exotic crayfish. Biological Invasions, 7, pp. 75-85, 2005. doi:10.1007/s10530-004-9636-7

[8] Corsi, I., Romani, R., Iacocca, A., Bonacci, S., Giovannini, E., Rosi, G. \& Focardi, S.E., Insecticides resistance in marine invertebrates: an evolutionary adaptation for successful colonization? Dissertation, 15th SETAC European Annual Meeting, Lille, pp. 278, 2005.

[9] Corsi, I., Pastore, A.M., Lodde, A., Palmerini, E., Castagnolo, L. \& Focardi, S.E., Potential role of cholinesterases in the invasive capacity of the freshwater bivalve, Anodonta woodiana (Bivalvia: Unionacea): a comparative study with the indigenous species of the genus, Anodonta sp. Comparative Biochemistry and Physiology C, 145, pp. 413-419, 2007.

[10] Romani, R., Corsi, I., Bonacci, S., Focardi, S.E., De Medico, G.E., De Santis, A., Incarnato, F., Giovannini, E. \& Rosi, G., Organophosphate-resistant forms of acetylcholinesterases in two scallops - the Antartic Adamussium colbechi and the Mediterranean Pecten jacobaeus. Comparative Biochemistry and Physiology B, 145, pp. 188-196, 2006. doi:10.1016/j. cbpb.2006.07.005

[11] Wicken, J.S., Information transformations in molecular Evolution. Jounal of Theoretical Biology, 72, pp. 191-204, 1978. doi:10.1016/0022-5193(78)90025-5

[12] Wicken, J.S., A thermodynamic theory of evolution. Journal of Theoretical Biology, 87, pp. 9-23, 1980. doi:10.1016/0022-5193(80)90216-7

[13] Wicken, J.S., An organismic critique of molecular Darwinism. Journal of Theoretical Biology, 117, pp. 545-561, 1985. doi:10.1016/S0022-5193(85)80237-X

[14] Wicken, J.S., Information, entropy and evolution: an agenda for dialogue. Journal of Social and Biological Structure, 9, pp. 275-277, 1986. doi:10.1016/S0140-1750(86)80030-6

[15] Ruesink, J.L., Parker, I.M., Groom, M.J. \& Karieva, P.M., Reducing the risk of the non-indigenous species introductions. Bioscience, 45, pp.465-477, 1995. doi:10.2307/1312790

[16] Williamson, M. \& Fitter, A., The characters of successful invaders. Biological Conservation, 78, pp. 163-170, 1996. doi:10.1016/0006-3207(96)00025-0

[17] Ellman, G.L., Courtney, K.O., Anders, J.R. \& Featherstone, R.M., A new and rapid colorimetric determination of acetylcholinesterases activity. Biochemical Pharmacology, 7, pp. 88-95, 1961. doi:10.1016/0006-2952(61)90145-9

[18] Bredford, M.M., A rapid and sensitive method for the quantitation of microgram quantities of protein utilizing the principle of protein-dye binding. Analitical Biochemistry, 72, pp. 248-254, 1976. doi:10.1016/0003-2697(76)90527-3 
[19] Nardi, F., Frati, F., Romani, R., Rosi, G., Corsi, I. \& Focardi, S.E., Organophosphate-resistance acetylcholinesterase in Mytilus galloprovincialis: identification of a resistance Ace gene in cerebral ganglion, gills and adductor muscle. Comparative Biochemistry and Physiology A, 151, pp. S2-S10, 2008.

[20] Talesa, V., Romani, R., Antognelli, C., Giovannini, E. \& Rosi, G., Soluble and membranebound acetycholinesterases in Mytilus galloprovincialis (Pelecypoda: Filibranchia) from the northern Adriatic sea. Chemical-Biological Interactions, 134, pp. 151-166, 2001. doi:10.1016/ S0009-2797(01)00152-1

[21] Talesa, V., Romani, R., Antognelli, C., Giovannini, E. \& Rosi, G., Different expressions of organophosphate-resistant acetylcholinesterases in the bivalve mollurk Scapharca inaequivalvis living in three different habitat. Environmental Toxicology and Chemistry, 21(1), pp. 102-108, 2002. doi:10.1002/etc.5620210115

[22] Randall, D., Burggren, W. \& French, K., Propagazione e trasmissione dell'informazione nervosa. Fisiologia Animale: meccanismi e adattamenti. Zanichelli, Milano, 2003.

[23] Tiezzi, E., Steps Towards an Evolutionary Physics. WIT Press Publications: Southampton and Boston, 2006.

[24] Fournier, D., Bride, J.M., Hoffmann, F. \& Karch, F., Acetylcholinesterase. Two types of modifications confer resistance to insecticide. Journal of Biological Chemistry, 267(20), pp. 14270-14274, 1992.

[25] Smith, G.R.T., Learner, M.A., Slater, F.M. \& Foster, J., Habitat features important for the conservation of the native crayfish Austropotamobius pallipes in Britain. Biological Conservation, 75, pp. 239-246, 1995. doi:10.1016/0006-3207(95)00073-9

[26] Naura, M. \& Robinson, M., Principles of using River Habitat Survey to predict the distribution of aquatic species: an example to the native white-clawed crayfish Austropotamobius pallipes. Aquatic Conservation: Marine and Freshwater Ecosystems, 8, pp. 515-527, 1998. doi:10.1002/(SICI)1099-0755(199807/08)8:4<515::AID-AQC261>3.0.CO;2-J 